\title{
Le titre FMH de spécialiste en infectiologie fête ses 10 ans
}

Ursula Maria Flückigera, Andreas Widmer ${ }^{b}$

a Prof., présidente de la Société suisse d'infectiologie

b Prof., secrétaire de la Société suisse d'infectiologie
1 Diamond J. Guns, Germs, and Steel: The Fates of Human Societies. W. W. Norton; 1997. ISBN 0-393-03891-2.

Correspondance:

Prof. Ursula Maria Flückiger Universitätsspital Basel Klinik für Infektiologie und Spitalhygiene Petersgraben 4

CH-4031 Base

Tel. 0612652525

Fax 0612653198

uflueckiger@uhbs.ch

www.sginf.ch
La «Société suisse d'infectiologie» a été créée le 13 novembre 1990 dans l'objectif d'encourager la recherche dans le domaine des maladies infectieuses et d'établir les critères de la formation postgraduée pour le titre FMH de spécialiste en infectiologie.

La création de ce titre suscita au début la controverse: une première requête a été rejetée, mais la complexité des modèles de thérapie contre le VIH au moyen de nouvelles substances antivirales et leurs nombreuses interactions, la propagation de bactéries multi-résistantes comme le staphylocoque doré résistant à la méticilline, la tuberculose multi-résistante, les infections complexes de corps étrangers et les nouvelles possibilités de diagnostic grâce à l'introduction de la réaction en chaîne par polymérase (PCR) ont été les raisons de la reconnaissance de notre spécialité.

Le travail fondamental des Prof. Michel Glauser et Claude Regamey a posé les bases de la création du titre de spécialiste. Les Prof. Werner Zimmerli et Andreas Widmer, président et secrétaire de l'époque, ne sont pas étrangers à cette avancée. Depuis 1999, soit depuis 10 ans cette année, l'infectiologie est dotée d'un titre de spécialiste FMH. Une particularité de notre société est de réunir en son sein des pédiatres et des médecins pour adultes.

Les spécialistes en infectiologie sont aujourd'hui présents dans la majorité des régions (cf. illustration). Dans le cadre du conseil en domaine hospitalier, l'infectiologie se consacre principalement au suivi lors de l'apparition d'infections postopératoires ou d'infections graves en médecine intensive, chez les patients après transplantation, immunosupprimés ou avec des infections de corps étrangers etc. Les entretiens interdisciplinaires entre les médecins traitants sont essentiels dans le but de cibler les analyses et thérapies sup- plémentaires à prescrire. En matière de diagnostics et de tests de sensibilité aux antibiotiques, la collaboration étroite avec les microbiologistes est primordiale. Coopérer avec les épidémiologistes hospitaliers revêt également de l'importance tout comme empêcher et traiter les infections nosocomiales. Un autre aspect de l'infectiologie réside dans le traitement des patients contaminés par le VIH. Grâce aux bonnes possibilités de thérapies actuelles, les patients séropositifs suivent principalement un traitement ambulatoire. L'étude suisse de cohorte VIH, une étude d'observation à long terme à laquelle participent des personnes infectées par le VIH-1, constitue un instrument d'excellente qualité pour les cliniques mais aussi pour la recherche fondamentale. Lancée en 1988, elle a considérablement relevé le niveau en matière de traitement et de recherche.

Pour toute question relative à l'épidémiologie, la contraception et le traitement des maladies infectieuses, les infectiologues sont des partenaires incontournables des autorités (OFSP, médecins cantonaux). Et précisément la propagation du virus grippal H1N1 montre la nécessité d'une collaboration forte et étroite entre les autorités, les infectiologues, les microbiologistes et les épidémiologistes afin de réussir à fournir des soins optimaux à la population.

Dans son livre, Jared Diamond résume en trois points les plus grandes influences exercées sur la destinée d'une société: «Guns, Germs, and Steel: The Fates of Human Societies» [1]. Les «germs» ou microorganismes auront aussi à l'avenir une forte influence sur notre vie et l'objectif de la Société d'infectiologie reste celui de s'engager sans relâche en faveur de la recherche, de nouveaux diagnostics et de nouvelles thérapies.

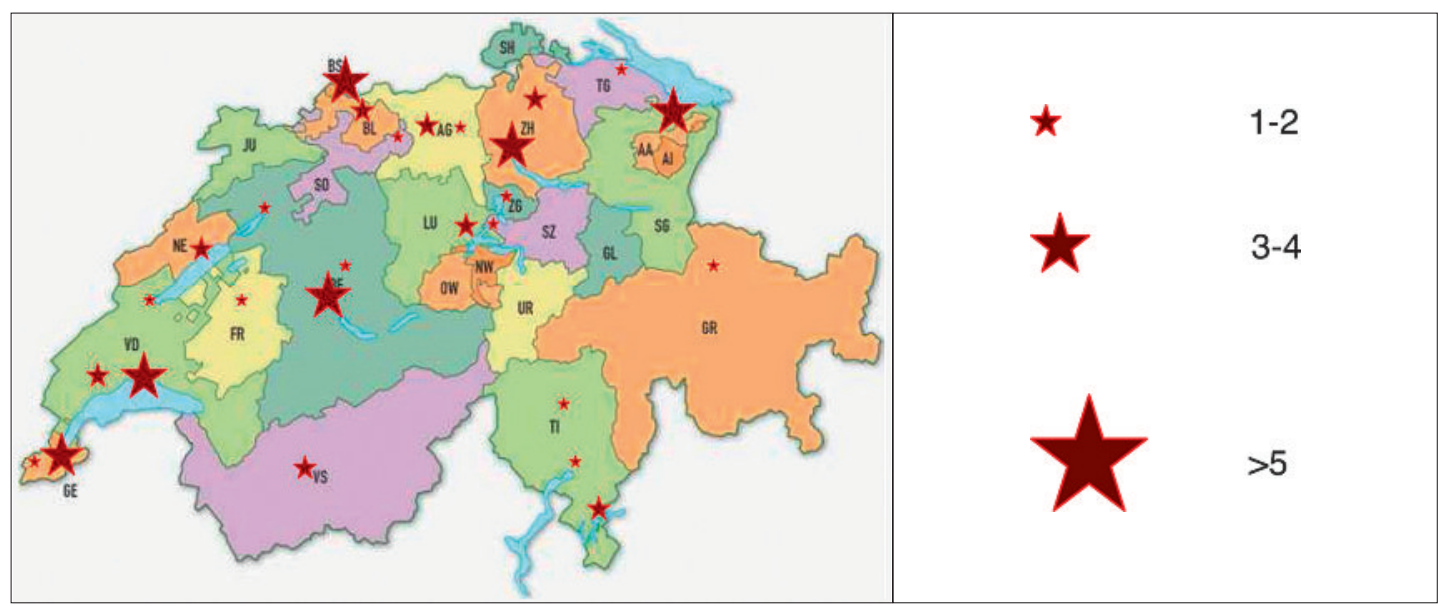

Nombre de spécialistes (membres ordinaires) de la Société suisse d'infectiologie. 